\title{
Influencia romano-germánica en el derecho tributario latinoamericano y, en particular, en la doctrina chilena. Análisis sincrónico y diacrónico para la discusión dogmática de hoy*
}

\author{
Roman-German Influence in the Latin American Tax Right and, in Particular, in the Chilean Doctrine. \\ Synchronous and Diachronic Analysis for the Dogmatic Discussion of Today
}

\author{
Antonio Faúndez-Ugalde ${ }^{\mathrm{a}}$ \\ Pontificia Universidad Católica de Valparaiso, Chile \\ antonio.faundez@pucv.cl \\ ORCID: http://orcid.org/0000-0002-8468-3042
}

DOI: https://doi.org/10.11144/Javeriana.vj139.irgd

Recepción: 21 Marzo 2018

Aceptación: 25 Junio 2019

Fecha de publicación: 30 Diciembre 2019

\section{Resumen:}

Este artículo presenta un estudio del impacto de las doctrinas romano-germánicas en el derecho tributario latinoamericano y, en particular, su influencia en el pensamiento de autores chilenos, distinguiendo aquellas discusiones que pueden ser incorporadas al debate actual, de aquéllas que solamente pueden ser consideradas como un antecedente histórico. Partiendo del análisis coherente y sistemático de las principales doctrinas romano-germánicas se establecerá, primero, la forma como fueron reconocidas en Latinoamérica. Después, se analizará la influencia que han generado en autores chilenos antiguos y de generaciones posteriores, determinando la presencia de escuelas dogmáticas o la elaboración de estudios que intentan organizar en un cuerpo ordenado de conocimiento. De acuerdo con lo anterior, los resultados esperados se centran en establecer que las doctrinas romano-germánicas no fueron reconocidas en América Latina de acuerdo a sus diferencias metodológicas, lo que tiene un impacto en los criterios argumentativos de las nuevas generaciones de autores chilenos.

Palabras clave: evolución histórica, derecho tributario, escuelas dogmáticas.

\begin{abstract}
:
This paper presents a study of the impact of Romano-Germanic doctrines on Latin American tax law and, in particular, its influence on the thinking of Chilean authors, distinguishing those discussions that can be incorporated into the current debate, from those that can only be considered as a historical antecedent. Starting from the coherent and systematic analysis of the main RomanGermanic doctrines, the way they were recognized in Latin America will be established first. Then, the influence that they have generated in ancient Chilean authors and of later generations will be analyzed, determining the presence of dogmatic schools or the elaboration of studies that try to organize an ordered body of knowledge. Following the above, the expected results are centered on establishing that the Roman-Germanic doctrines were not recognized in Latin America regarding their methodological differences, having an impact on the argumentative criteria of the new generations of Chilean authors.
\end{abstract}

Keywords: historical evolution, tax law, dogmatic schools.

\section{Introducción}

Si se analizan las incipientes colecciones de estudios jurídicos y sociales editadas por la Universidad de Chile, sabremos que la primera monografía vinculada al ámbito de la tributación es la obra del autor Álvaro Rencoret titulada Derecho tributario, el impuesto sobre la renta, publicada en el año 1950, donde manifiesta en el prólogo que su obra no se sustenta en bibliografía alguna porque en dicho ámbito del derecho prácticamente no existe $^{[1]}$. Este hito debe ligarse con la circunstancia de que hasta el año 1948 en la Facultad de Ciencias Jurídicas y Sociales de la Pontificia Universidad Católica de Chile \#casa de estudio en la cual Rencoret era

Notas de autor

\footnotetext{
a Autor de correspondencia. Correo electrónico: antonio.faundez@pucv.cl
} 
docente\# se dictaba la cátedra de hacienda pública y recién en el año 1949 comenzó a impartirse en esa casa de estudios el curso de derecho tributario. Un reconocimiento similar fue expresado por el autor Enrique Piedrabuena en su obra titulada Manual de derecho financiero, publicada en el año 1950, donde indica que, hasta ese entonces, el derecho tributario científicamente no era todavía ciencia ${ }^{[2]}$.

Antes de las obras de Rencoret y Piedrabuena, solamente se presentaban autores que desarrollaron una temática vinculada a los impuestos que regían en aquel tiempo como, por ejemplo, la obra de Patricio Barros Lynch titulada Un cuarto de siglo de legislación tributaria en Chile, aparecida en 1927. En cambio, con posterioridad, comienzan a aparecer las primera obras con un contenido un poco más extenso en bibliografía, proveniente principalmente de corrientes romano-germánicas, lo que marcó la revelación de las primeras escuelas de derecho tributario extranjeras que inspiraron a los autores chilenos de aquel momento. Así destacan, mayormente, autores italianos como Benvenuto Griziotti, Oreste Ranelletti, Achille Giannini, Antonio Berliri, Gustavo Ingrosso, Mario Pugliese, Dino Jarach, entre otros.

Como se verá, la marcada influencia de la doctrina italiana no solamente impactó en Chile, sino que también en toda Latinoamérica, en donde se destacan, particularmente, las corrientes detractoras entre Benvenuto Griziotti y Oreste Ranelletti. Benvenuto Griziotti, fundador de la escuela económica y jurídico-financiera de Pavía, observó que los estudiosos financieros necesariamente debían desarrollar sus postulados considerando una "integridad" temática basada en la orientación política, el fundamento jurídico, el contenido económico y la ordenación científica de los institutos financieros. Esta concepción integralista plantea que el fenómeno tributario debe ser examinado simultáneamente en todos sus aspectos, en base a un método sincrético y de metodología de interpretación funcional ${ }^{[3]}$. Por su parte, la metodología de estudio de Oreste Ranelletti se basó en que la investigación del jurista es distinta de la del economista, pero las materias económicas constituyen un presupuesto básico para el estudio de las materias jurídicas; de esta forma, distinguió el derecho financiero de la ciencia de las finanzas ${ }^{[4]}$.

Lo anterior representó, marcadamente, dos escuelas con distintos seguidores, las que no alcanzaron a ser percibidas por los autores chilenos, justificando, de esta forma, la problemática a desarrollar en esta investigación.

Así, las hipótesis de trabajo cuya validez y consecuencias pretenden ser demostradas en esta investigación, son las siguientes: primero, la mayoría de los países latinoamericanos recogieron las corrientes romanogermánicas, primando, hasta nuestros días las escuelas que promueven la teoría del hecho imponible; segundo, es posible sostener que en la evolución histórica de la doctrina chilena de derecho tributario desde comienzos del siglo xx se desarrolló sin considerar las corrientes detractoras de la doctrina tributaria italiana; $y$, tercero, es posible sostener que las primeras obras de autores tributaristas chilenos publicadas durante la primera mitad del siglo xx sirvieron de fuente de inspiración para los autores chilenos de la segunda mitad de ese siglo, pero con el mismo desconocimiento de las referidas corrientes opositoras italianas que, en aquel entonces, eran irreconciliables.

Los objetivos específicos se concentran, primero, en sistematizar la totalidad de la producción de la doctrina tributaria chilena desde la ley sobre impuesto a la renta estatuida en Chile en el año 1924, identificando las influencias nacionales y extranjeras recibidas. Segundo, investigar los sucesos del pasado para establecer, desde un punto de vista sincrónico, las influencias recibidas por los autores tributaristas chilenos y su aporte a la discusión nacional al tiempo de su publicación, y, desde un punto de vista diacrónico, establecer el impacto de dichas obras en los postulados de las nuevas generaciones de autores. Finalmente, a partir del examen exhaustivo de la doctrina tributaria chilena, establecer si de ella cabe posicionar la existencia de escuelas dogmáticas, o bien, solamente la elaboración de estudios sistemáticos que se puedan incorporar al debate actual. 


\section{Influencia romano-germánica en el derecho tributario latinoamericano}

En la primera mitad del siglo xx, bajo el alero de corrientes romano-germánicas, se presentó uno de los debates doctrinarios más importantes relacionados con la tributación, pero condicionado a los estudios científicos y didácticos del derecho financiero. Esta riquísima discusión doctrinaria principió con la posición integralista del italiano Benvenuto Griziotti, continuando, más o menos en el mismo lapso, con las corrientes detractoras de la escuela napolitana encabezada por su compatriota Oreste Ranelletti.

Benvenuto Griziotti ${ }^{[5]}$, fundador de la escuela económica y jurídico-financiera de Pavía, observó que los estudiosos financieros necesariamente debían desarrollar sus postulados considerando una integridad temática basada en la orientación política, el fundamento jurídico, el contenido económico y la ordenación científica de los institutos financieros. Esta concepción integralista, a la luz de la cual el aludido fenómeno debe ser examinado simultáneamente en todos sus aspectos, constituyó el denominado método sincrético y la metodología de interpretación funcional ${ }^{[6]}$. Si se hace un análisis de la principal obra de Griziotti titulada Principios de política, derecho y ciencia de la hacienda, publicada en 1933, encontramos que, en su criterio, el derecho no solamente es forma, sino que también es sustancia de la propia relación financiera entre el Estado y los sometidos a su soberanía. Agrega que, en la formación del derecho financiero influirían relaciones éticas, políticas y económicas del impuesto y de los demás institutos financieros, y en el derecho financiero se sustancia la soberanía del Estado sobre los contribuyentes. De ahí -indica- que el derecho no podría prescindir del conocimiento de los elementos políticos, morales y económicos del impuesto y de los demás institutos financieros, del mismo modo que la ciencia de la hacienda y la política financiera no pueden ignorar el derecho financiero como elemento esencial de la relación entre el Estado y sus contribuyentes ${ }^{[7]}$.

Por otro lado, la metodología de estudio de Oreste Ranelletti ${ }^{[8]}$ se basó en que la investigación del jurista es distinta de la del economista, pero las materias económicas constituyen un presupuesto básico para el estudio de las materias jurídicas. De esta forma, distinguió el derecho financiero de la ciencia de las finanzas. Esta concepción tuvo en común con la de Griziotti la apreciación unitaria del fenómeno financiero, pero se diferenciaba de aquella porque Ranelletti consideraba que la ciencia económica constituía un presupuesto fundamental para el estudio de los aspectos jurídicos del fenómeno, pero no pretendía que economistas y juristas estudiaran integralmente, y en un solo curso, todos los aspectos del fenómeno financiero ${ }^{[9]}$.

Los postulados de Ranelletti sirvieron de base a importantes juristas italianos, entre quienes destacan: Francesco D’Alessio $^{[10]}$, Gustavo Ingrosso ${ }^{[11]}$; Vicenzo Romanelli-Grimaldi ${ }^{[12]}$; Vincenzo Sica ${ }^{[13]}$ y Guiseppe Abbamonte ${ }^{[14]}$, cuyos trabajos lograron un gran avance para las concepciones de la escuela jurídico-financiera napolitana.

Sin embargo, el desprendimiento del derecho tributario del derecho financiero comenzó paulatinamente a desarrollarse con las investigaciones realizadas por el autor italiano Achille Donato Giannini ${ }^{[15]}$, quien, acogiendo sustancialmente el método de Oreste Ranelletti, estableció nuevas metodologías de estudio del derecho tributario sobre la base de lo que denominó como la relación jurídico-tributaria ${ }^{[16]}$. Esta metodología también fue asumida por importantes juristas de mediados del siglo $\mathrm{xx}$, entre quienes se encuentran sus compatriotas Antonio Berliri ${ }^{[17]}$ y Mario Pugliese ${ }^{[18]}$. Giannini ${ }^{[19]}$ reconoció en su obra Instituciones de derecho tributario que en Italia se carecía de una ley general que estableciera los principios fundamentales del derecho tributario, e indicó que dicha rama tuvo su iniciación en la literatura alemana ${ }^{[20]}$, principalmente bajo el impulso de la promulgación de la Ley general tributaria (Reichabgabenordnung, también conocida como la RAO del 13 de diciembre de 1919, redactada nuevamente el 22 de mayo de 1931. Esta ley hizo el primer reconocimiento de los principios fundamentales del derecho tributario, comprendió de 488 artículos sobre organización financiera; los elementos constitutivos de la relación tributaria; la liquidación y la recaudación de la deuda impositiva; sanciones por violación a los deberes fiscales; y sobre su aplicación ${ }^{\text {[21] }}$. 
Según Lobo ${ }^{[22]}$, la generación italiana que escribió entre los años 1937 y 1955, aproximadamente, incorporó y divulgó las orientaciones básicas de la doctrina germánica para los países latinos, por un lado, en la línea de la jurisprudencia de los intereses y de la consideración económica del denominado hecho generador, desarrollada por Enno Becker, que repercutieron en las obras de Vanoni ${ }^{[23]}$ y de Griziotti, y, por otro lado, en la línea de la llamada relación jurídica tributaria, defendida por autores como Albert Hensel ${ }^{[24]}$, Hans Nawiasky ${ }^{[25]}$ y Ernst Blumenstein ${ }^{[26]}$, que influenciaron las obras de Giannini.

Los aportes de Giannini tuvieron gran influencia en la Ley general tributaria española de 1963, elaborada por el jurista Fernando Sainz de Bujanda ${ }^{[27]}$. Esta ley, con la contribución de los profesores Ramón Valdés ${ }^{[28]}$, de Uruguay; Carlos Fonrouge ${ }^{[29]}$, de Argentina; y Rubens Gomes de Sousa ${ }^{[30]}$, de Brasil, entre otros, inspiró a su vez la publicación del Modelo de Código Tributario para América Latina ${ }^{[31]}$ de 1967, proceso en el cual tuvo influencia la labor docente y científica de los juristas italianos Mario Pugliese y de Dino Jarach ${ }^{[32]}$, quienes transmitieron el pensamiento de Giannini y de Benvenuto Griziotti ${ }^{[33]}$. No obstante, cabe advertir que, si bien Pugliese y Jarach fueron alumnos de Grizziotti, éstos consideraron en sus estudios la metodología desarrollada por Oreste Ranelletti ${ }^{[34]}$.

Pugliese es el autor de Istituzioni di diritto finanziario, publicada en 1937. En 1939 se trasladó a Argentina para impartir el curso de derecho financiero en la Universidad de Córdoba, donde murió en 1940. Lo sucedió, por la indicación de Griziotti ${ }^{[35]}$, Dino Jarach, quien es el autor de dos obras consideradas clásicas en la materia: Curso superior de derecho tributario, de 1957, y El hecho imponible, publicada en $1943^{[36]}$. Fue precisamente en esta última obra en que Jarach desarrolló el denominado concepto del hecho imponible, indicando que, por voluntad de la ley, la obligación del contribuyente y la prestación correlativa del fisco se hacen depender del verificarse un hecho jurídico, el denominado presupuesto legal del tributo, o hecho imponible ${ }^{[37]}$. Sin embargo, en la elaboración de su teoría, Jarach siguió una posición opuesta a Giannini y Pugliese en lo que se refiere a la relación jurídico-tributaria, planteando que sería un error considerarla como una relación compleja que agrupa diferentes relaciones sustantivas y formales que constituyen el derecho tributario material y el formal. Al contrario, Jarach sostiene que la relación jurídica principal y las demás relaciones jurídicas accesorias son de naturaleza completamente distinta ${ }^{[38]}$.

La teoría del hecho imponible también fue objeto de críticas, aunque fue el propio Jarach quien asumió algunas impropiedades en su análisis, señalando:

“(...) estoy dispuesto a reconocer que la expresión es, quizá, errónea, porque habla de hecho cuando muchas veces se trata de un conjunto de hechos o circunstancias de hecho; porque habla de 'imponible', y el adjetivo con la terminación 'ble' indica una idea de posibilidad, cuando en realidad sabemos que es un conjunto de hechos que hace nacer, indefectiblemente, la pretensión del tributo y la obligación. De manera que no es 'imponible', sino 'impuesto'. Es un hecho sobre el que recae el gravamen sin posibilidad o facultad de someterlo o no a gravamen. Está gravado"[39].

Sin embargo, la obra de Jarach plantea ambigüedades en cuanto a posicionar la expresión hecho imponible en el ámbito de las normas jurídicas generales y abstractas, lo que sería un contrasentido si es asimilada a los hechos jurídicos. Así lo indica en el prólogo de la segunda edición: "que las normas que definen los hechos imponibles en todos sus aspectos y crean las obligaciones de los contribuyentes hacia el fisco..." ${ }^{[40]}$. Un hecho jurídico ocurre en un momento, en un lugar y por un sujeto determinado, lo que es imposible que sea descrito por las normas generales y abstractas; estas últimas no definen hechos jurídicos sino hipótesis o supuestos hipotéticos.

Estas impropiedades que se desprenden de obra Hecho imponible fueron clarificadas por Jarach con posterioridad en un artículo titulado Estrutura e elementos da relação jurídico-tributária, publicado en Brasil en la Revista de direito público, en el año 1971, manifestando que 
“(...) la característica fundamental del hecho imponible consiste, pues, en su naturaleza de hecho jurídico, al que la ley vincula el nacimiento de la obligación. A ese respecto, se debe decir que la obligación nace de la ley, cuando se verifica el hecho imponible, por la existencia, en la vida real, de un hecho imponible que se pueda subsumir en la definición legal. Por otra parte, el hecho imponible no crea, por sí solo, la obligación, sino que lo hace a través de la ley. Esta conexión \#entre hecho imponible y la norma que es fuente de la obligación\# tiene como consecuencia ineludible la de ser el hecho imponible un hecho jurídico. Es decir, un hecho productivo de efectos jurídicos, por voluntad de la ley”[41].

Se desarrolla, aquí, su intención de ubicar el hecho imponible fuera del campo de las normas generales y abstractas, calificándolo como un hecho jurídico. Esta misma orientación dejó asentada en la asamblea del II curso de especialización en derecho tributario, desarrollada en Brasil en el año 1971 y publicada en el año 1975, en donde señala lo siguiente:

"[...] de modo que no hay oposición entre la interpretación de la ley y la interpretación del hecho imponible (como decimos, en la terminología española, que se adopta ahora); siempre existe la interpretación de uno y de otro. La ley establece, por conceptos normativos, el presupuesto de la obligación que, por definición, es un concepto abstracto; ésta tendrá eficacia en el caso concreto, cuando se verifiquen, en la vida real, los hechos y las conductas humanas, económicas y sociales, los hechos que son definidos en forma abstracta por la ley y, por tanto, la interpretación siempre tendrá, como su norte, tanto la identificación del hecho real como la hipótesis definida por la ley"[42].

Si bien Jarach aceptó las críticas formuladas a su teoría, marcó gran influencia en países como Venezuela y Argentina. El autor argentino Héctor Villegas, en su Curso de finanzas, derecho financiero y tributario, señala:

“[...]resulta difícil, en un texto con pretensiones didácticas, 'desdoblar' la tradicional denominación acuñada por Jarach. Por eso continuamos utilizando la expresión 'hecho imponible’ para denominar la hipótesis legal tributaria condicionante. Hablaremos \#en cambio\# de hecho imponible 'realizado' o 'configurado' cuando ello sea necesario para indicar que nos estamos refiriendo al hecho ocurrido o a la situación producida con respecto a la persona y en el lugar y tiempo que previamente fueron hipotéticamente descritos por el legislador" ${ }^{\text {[43] }}$.

Esto demuestra las impropiedades que ha generado la teoría del hecho imponible de Jarach, en el sentido de que su análisis tiende a abarcar, de manera incorrecta, dos ámbitos completamente distintos, uno, el de las normas jurídicas generales y abstractas y, otro, el mundo de los hechos ocurridos en un tiempo y espacio determinado y por un sujeto determinado. Esta problemática se genera en la falta de precisión de la función que cumplen los hechos en el derecho. Situación similar se presenta con la teoría del hecho generador, expresión que terminó por posicionarse en la mayoría de los países latinoamericanos.

La teoría del hecho generador fue desarrollada mayormente en Brasil por influencia del francés Gaston Jèze, cuyas lecciones tuvieron gran divulgación en ese país ${ }^{[44]}$. La traducción al portugués de la obra de Jezè estuvo a cargo de Paulo da Mata en el año 1945, definiendo hecho generador como

“[...]la reunión, en un individuo determinado, de todas las condiciones enumeradas por la ley orgánica de impuesto para que los agentes de la determinación (o liquidación) ejerzan su competencia (obligatoria) de decidir que ese individuo es deudor, ante el Fisco, da tal importancia en dinero, a título de tal impuesto" ${ }^{[45] .}$

Sin embargo, lo que en un comienzo se posicionaba como una nueva corriente en Brasil, la expresión becho generador se consideró como equivalente a otros términos que había desarrollado la doctrina, como el denominado becho imponible, pero prefiriéndose el primero por sobre el segundo en atención a que ya había entrado en la terminología de ese país ${ }^{[46]}$. Así también quedó plasmado en las comisiones especiales legislativas de Brasil en las que se discutió el anteproyecto del Código Tributario Nacional del año 1966, elaborado por Rubens Gomes de Sousa ${ }^{[47]}$. Por lo demás, hasta ese entonces en Brasil, la doctrina ya había consultado la obra de Jarach, quien, a su vez, también había considerado publicaciones de Gaston Jezè en la bibliografía de su obra El hecho imponible. 
El término hecho generador también impactó en la legislación de países de Latinoamérica como Uruguay $^{[48]}$, Perú ${ }^{[49]}$, Bolivia ${ }^{[50]}$, Colombia ${ }^{[51]}$, Ecuador ${ }^{[52]}$ y Paraguay ${ }^{[53]}$, primando, asimismo, en el Modelo de Código Tributario para América Latina del año 1967. Aunque cabe recordar que en dicho proyecto fue influenciado por la labor docente y científica de los juristas italianos Mario Pugliese y de Dino Jarach, lo que comprueba que entre el hecho generador y el hecho imponible no existe gran diferencia sustancial.

\section{Impacto del derecho tributario romano-germánico en el derecho chileno}

En Chile, los primeros tributos instaurados bajo la dependencia de la corona española, desde 1545 a 1810, estaban destinados a beneficiar tanto a la Iglesia como al gobierno. Conquistada la libertad política, y como consecuencia de la precaria situación de las finanzas y las necesidades crecientes del país, llevaron al primer gobierno nacional y a los que le siguieron, a establecer nuevos tributos. De esta manera, en 1820, se presentó la primera manifestación de tributos a la obtención de renta por empleados públicos, el que, según Carvallo ${ }^{[54]}$, más que un texto impositivo fue una ley de ahorro obligatorio.

Frente a las contingencias de la guerra con España, en 1866 se estableció un tributo sobre las rentas del 5\%, y hacia el año 1879, por la incorporación de la riqueza del salitre a la economía chilena, derivó en la abolición de gran parte de los tributos internos. Sin embargo, como consecuencia de la crisis económica que comenzó a golpear a Chile desde la primera mitad de 1890, se planteó una discusión en torno a la necesidad de contar con nuevas entradas fiscales. Así, el mayor cambio en términos de los ingresos fiscales fue, sin duda, el impuesto a la renta, el que si bien ya existía uno establecido hacia 1915, éste no era muy significativo y estaba latente la necesidad de aumentar los impuestos internos en el ministerio de hacienda ${ }^{[55]}$.

La primera moción de un impuesto sobre la obtención de la renta fue presentada el 4 de junio de 1919 , por los diputados Víctor Robles, Héctor Arancibia Laso, Galvarino Gallardo Nieto y Remigio Medina, en la primera sesión ordinaria de la Cámara de Diputados, que propiciaba un impuesto de carácter progresivo. Si bien esta moción no prosperó ante la Cámara de Diputados, en ese mismo año se presenta una segunda moción, pero esta vez a cargo del Ministro de Hacienda Luis Claro Solar. En este proyecto no se reconoció una fuente de inspiración particular, sin embargo, en su presentación ante la Cámara, se esbozaron corrientes de autores británicos como William Gladstone, respecto del tratamiento del concepto de renta. Este proyecto tampoco tuvo éxito en su tramitación, siendo finalmente desechado.

Posteriormente, el diputado Jorge Silva Somarriva presentó un nuevo proyecto de ley en 1921, el cual sirvió de sustento al proyecto elaborado por la Comisión de Hacienda de la Cámara de Diputados el 5 de abril de 1922, tuvo como fuente principal el sistema francés sancionado en $1914^{[56]}$. En diciembre de 1923 fue aprobado en forma definitiva un impuesto sobre la obtención de la renta, promulgándose la ley el día 2 de enero de 1924, bajo el número 3.996 ${ }^{[57]}$. Según Mena y Charad ${ }^{[58]}$, los textos legales anteriores a esta ley no pueden ser considerados como efectiva implantación de este tributo, sino como simples arbitrios circunstanciales destinados a improvisar recursos de emergencia a las arcas públicas. Asimismo, si bien dicha ley tuvo como base el sistema francés, tampoco se puede atribuir el nacimiento de una ciencia del derecho relacionada al ámbito tributario, atendido a que el sistema instaurado respondía a fundamentos propios de las ciencias económicas. Así, los primeros textos publicados en la primera mitad del siglo XX obedecieron a una descripción de los efectos o alcances del texto legislado ${ }^{[59]}$, pero no configuraron una teoría propiamente, si por teoría se entiende "[...] ]una construcción que intenta organizar de manera sistemática y completa un cuerpo de conocimiento" ${ }^{\text {[60] }}$.

Así, si se revisan las primeras colecciones de estudios jurídicos y sociales editadas por la Universidad de Chile $^{[61]}$, se desprende que la primera monografía vinculada al derecho tributario es la obra del autor Álvaro Rencoret $^{[62]}$ titulada Derecho tributario, el impuesto sobre la renta, publicada en el año 1950, manifestando 
en su prólogo que su obra no se sustenta en bibliografía alguna porque en materia sobre impuesto a la renta, prácticamente no existe ${ }^{[63]}$. También en el año 1950 apareció, en carácter de manual, la obra del autor Enrique Piedrabuena ${ }^{[64]}$ titulada Manual de derecho financiero, pero que solamente representa una obra limitada al derecho tributario y no al derecho financiero propiamente tal, reconociendo en su prólogo que, hasta ese entonces, el derecho tributario científicamente no era todavía ciencia ${ }^{[65]}$. La bibliografía utilizada para el desarrollo de su obra no contempló las metodologías de estudio que hasta ese entonces se venían desarrollando en Italia y en Alemania, ni tampoco diferenciando las distintas corrientes que se presentaron en la primera mitad del siglo XX.

En el año 1951 se publica la obra ¿Cómo hacer la declaración para el impuesto a la renta?, del autor Osvaldo Torres, que solamente tiene un enfoque práctico destinado al cumplimiento tributario ${ }^{[66]}$.

En este andar, llegamos al año 1952, fecha en la cual se publica la primera obra que recoge frugalmente las corrientes italianas desarrolladas hasta aquel entonces, me refiero a la monografía de los autores Mario Fernández y Héctor Fernández ${ }^{[67]}$ titulada Principios de derecho tributario. De este libro se destaca la metodología utilizada por Achille Giannini en relación a la obligación tributaria, citando también la obra Instituciones de derecho financiero de Mario Pugliese. A través de dichos autores italianos llegan a los postulados de Benvenuto Griziotti y de Ernst Blumenstein, sin lograr percibir las corrientes detractoras del autor italiano Oreste Ranelletti. Asimismo, los autores hacen la salvedad de que al término de la redacción de su obra tomaron conocimiento del trabajo desarrollado por Dino Jarach titulado El hecho imponible, sin embargo, estructuran igualmente su obra en base a lo que ellos denominan como hecho gravado ${ }^{[68]}$.

Haciendo una relación con lo analizado anteriormente, se puede detectar que los autores Mario Fernández y Héctor Fernández recopilaron autores italianos de corrientes metodológicas opuestas \#entre Benvenuto Griziotti y Achille Giannini, este último seguidor de Oreste Ranelletti\#, creando, luego, una institución con apego a la relación jurídico-tributaria de Giannini, que denominaron hecho gravado. Así, estos autores comenzaron el estudio del hecho gravado y lo situaron en el plano de los hechos jurídicos tributarios, como se desprende del primer capítulo de la segunda parte de su libro, bajo el acápite "Concepto del hecho gravado", en donde señalan que "[...] antes de que ese hecho ocurra, aun cuando puedan existir deberes u obligaciones de policía tributaria o de otra índole, no habrá obligación tributaria de enterar en la caja de un ente público

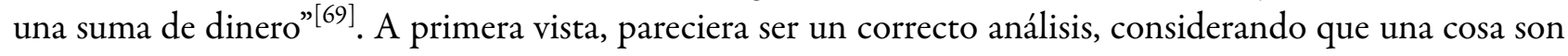
los enunciados del texto de la ley que se refieren a posibles sucesos y que sirven de soporte a las normas jurídicas y, otra, son los acontecimientos que se presentan en el mundo físico que serán percibidos por un acto de aprehensión sensorial ${ }^{[70]}$. Sin embargo, el lugar que en un comienzo estos autores posicionan al hecho gravado, esto es, vinculado con el mundo físico, a medida que avanzan en el análisis, sin darse cuenta, van centrando su relato en los enunciados del texto de la ley, como ocurre en la quinta parte de su obra, en donde señalan: "Ya hemos dicho que la ley tributaria se limita a señalar el hecho gravado"[71]. Esto comprueba los serios inconvenientes que produce la aplicación de dicho enunciado.

Dos años después de la publicación de los Principiosde Mario Fernández y Héctor Fernández, se publica un segundo manual en las colecciones de estudio de la Universidad de Chile, en dos tomos, titulado Derecho financiero, pero ahora a cargo de los autores Víctor Mena Vergara ${ }^{[72]}$ y Emilio Charad Dahud ${ }^{[73]}$, texto que formó parte del desarrollo de la cátedra de derecho financiero impartida en aquella época por la Facultad de Ciencias Jurídicas y Sociales de la Universidad de Chile. En el primer tomo, los autores realizan un análisis integrado de la ciencia de las finanzas y el derecho financiero, con una marcada influencia de juristas franceses, dejando para el segundo tomo el estudio del derecho tributario, pero limitado solamente a los principales impuestos vigentes en dicho período. Esta obra tampoco logró percibir las distintas doctrinas romano-germánicas desarrolladas en esta etapa.

Hasta aquí podemos situar a los citados autores chilenos como aquellos que entregaron los primeros indicios doctrinarios para el ámbito del derecho tributario, al recopilar de manera frugal las corrientes 
romano-germánicas, pero sin lograr percibir las distintas metodologías de estudios desarrolladas hasta dicho momento. El hito más relevante se encuentra en la teoría del hecho gravado, elaborada por Mario Fernández y Héctor Fernández, que fue considerada como presupuesto para el nacimiento de la relación jurídico-tributaria de Giannini y que influenció a las posteriores generaciones de autores, como se verá a continuación.

\section{Impacto de las corrientes antiguas del derecho tributario chileno en las generaciones posteriores}

En los primeros años de la segunda mitad del siglo XX se publicaron obras con un análisis normativo y jurisprudencial de las leyes tributarias, pero algunas de ellas desprovistas de fuente bibliográfica ${ }^{[74]}$ y otras con frugal literatura que no consideró las corrientes romano-germánicas de derecho tributario ${ }^{[75]}$.

En el año 1969 se publica una de las obras más destacadas en la doctrina chilena, la que ha servido de base para los estudios del derecho tributario en estos últimos tiempos, esto es, la obra del autor Pedro Massone ${ }^{[76]}$ titulada El hecho jurídico tributario. Massone sostiene en dicha monografía que el derecho tributario debe basarse en la teoría general del hecho jurídico ${ }^{[77]}$, sustentando su posición, mayormente, en autores italianos como Antonio Berliri, Achille Giannini, Benvenuto Griziotti, Gustavo Ingrosso, Mario Pugliese y Dino Jarach.

Este libro se estructura, en la primera parte, con un análisis genérico de las normas jurídicas y los hechos jurídicos, y casi en la mitad del texto comienza el estudio del hecho jurídico tributario, que establece como parte de su contenido cinco elementos: el suceso o hecho como tal, con una situación inicial, un cambio y una situación final; el contenido económico; la vinculación personal; la previsión legal; y el efecto jurídico tributario. Se aprecia en esta obra de Massone el gran apego a la teoría del hecho imponible de Jarach, aunque precisa que prefiere hablar de hecho jurídico tributario ${ }^{[78]}$. Si bien en la fuente bibliográfica no se encuentra Los principios de Mario Fernández y Héctor Fernández, igualmente postula que el hecho jurídico tributario correspondería a lo que la doctrina denomina como hecho gravado ${ }^{[79]}$.

La misma metodología asume en su obra Principios de derecho tributario, publicada en primera edición en 1975 y en segunda edición en 1979, en donde considera fundamental el estudio del hecho jurídico tributario para explicar el efecto jurídico del nacimiento de la obligación tributaria ${ }^{[80]}$. En el año 2013, Massone publica la tercera edición de sus Principios tres años después la cuarta edición, en la cual incorpora una innovadora escuela de derecho tributario desarrollada en Brasil bajo el alero del autor Paulo de Barros ${ }^{[81]}$.

Nuestro autor sostiene en la citada obra, que uno de los elementos del hecho jurídico tributario es la previsión legal, haciéndose partícipe de las corrientes doctrinarias del hecho generador o del hecho imponible, cometiendo el mismo error que en Los principios de Mario Fernández y Héctor Fernández. Massone reconoce

"[...]por efecto del principio de legalidad, la necesidad de que en la ley formal estén determinados, por lo menos, los siguientes elementos: el hecho generador del tributo o hecho jurídico tributario, la correspondiente base de cálculo, la tasa o alícuota y los sujetos pasivos directos e indirectos de la obligación tributaria" ${ }^{\text {[82] }}$

luego, haciendo eco de la obra de Almícar de Araujo Falcao, titulada El hecho generador de la obligación tributaria, señala que "definir, caracterizar, conceptuar por ley el hecho tributario, es por lo tanto, uno de los aspectos más destacados del llamado principio de legalidad de los tributos, o de reserva de ley en materia tributaria" ${ }^{\prime[8]}$.

Esta última visión también refleja imprecisiones. El hecho jurídico tributario identifica en forma específica a una persona, con nombre o razón social determinada, que se constituirá en el sujeto pasivo de la obligación tributaria, quien, a contrario sensu, nunca estará especificado o previsto en el texto de la ley. Por lo tanto, la previsión legal que da sustento al principio de legalidad, en estricto rigor, no puede ser encaminada a 
la luz de los hechos jurídicos tributarios, en atención a que la previsión de éstos se despliega a partir de los acontecimientos ocurridos en el mundo real, eventos que se verifican en un momento determinado, desvaneciéndose en ese mismo instante, sin que vuelvan jamás a ocurrir. Siendo así, la ley comprende situaciones hipotéticas que regulan para el futuro. Es por esto que Massone incurre en un error al establecer como elemento del hecho jurídico tributario una situación inicial que identifica como una porción de la realidad a la que norma jurídica hace referencia ${ }^{[84]}$. La norma jurídica general y abstracta no puede describir una porción de la realidad, de lo contrario regularía un hecho que ha ocurrido en un tiempo y espacio determinado, salvo que ese sea su propósito como, por ejemplo, una ley de amnistía referida a hechos ocurridos en un tiempo pasado.

Massone indica que "[...] es necesario distinguir el hecho tributario que está en la ley y el hecho tributario que está en el mundo" ${ }^{[85]}$. Justifica este proceder en los siguientes términos:

\begin{abstract}
"en este y en algunos otros casos usaré la expresión 'hipótesis hecho' para referirme, a la vez, a la hipótesis y al hecho, siguiendo el uso de palabras o expresiones extranjeras que tienen este doble significado (Tatbestand, fattispecie). Habrá ocasiones en que también lo usaré, para traducir esas palabras extranjeras o para significar tanto la hipótesis abstracta, como el hecho concreto que se ajusta a la primera, porque hay casos, en que lo que se predica vale tanto para la hipótesis tributaria como para el hecho tributario, pero sin perder de vista que se trata de dos conceptos y planos diferentes" ${ }^{\text {[86] }}$.
\end{abstract}

Es aquí en donde resalto la crítica al pensamiento de Massone. La hipótesis jurídica tributaria y el hecho jurídico tributario pertenecen a planos distintos y, en eso, Massone también coincide. Sin embargo, para establecer la precisión terminológica que todo trabajo científico requiere, el estudio del contenido jurídico de estas instituciones no se puede concretar en forma conjunta. Es un error afirmar que "[...]el hecho sea un reflejo o espejo de la hipótesis" ${ }^{[87]}$ y, de ello, que sea válido su tratamiento conjunto. El hecho jurídico tributario cuenta con sus propios elementos, que son semejantes a los criterios de la hipótesis jurídica tributaria, pero no iguales. En el plano de la geometría, dos figuras son semejantes, cuando son distintas en su tamaño, pero que de cierta forma sus partes guardan la misma proporción; por otro lado, que dos figuras sean iguales, implica que se pueden superponer de modo que coincidan en su totalidad. Espejo, entonces, significa que dos cosas son iguales, lo que no sucede entre el hecho jurídico tributario y la hipótesis jurídica tributaria. En el plano del hecho jurídico tributario existirá siempre un sujeto plenamente identificado (por ejemplo: "Rómulo percibió una renta"), un tiempo ocurrido (por ejemplo: "Rómulo percibió una renta el $1^{\circ}$ de febrero de 2014") y un lugar específico (por ejemplo: "Rómulo percibió una renta el 1º de febrero de 2014, en la ciudad de Valparaíso"), elementos que no forman parte de las normas generales y abstractas (por ejemplo: "si el domiciliado en Chile percibiere rentas, de fuente chilena o extranjera, en un año comercial"). En esto radica la necesidad de estudiarlos en forma separada.

En resumen, la teoría del hecho jurídico tributario planteada por Massone se vincula a la metodología asumida por autores como Jarach, sin percibir las corrientes detractoras entre Benvenuto Griziotti y Oreste Ranelletti. En tal sentido, la teoría del hecho jurídico tributario de Massone presenta contradicciones que dificultan un planteamiento coherente en su relación con las normas jurídicas generales y abstractas, lo que ha incidido, junto con la teoría del hecho gravado de Mario y Héctor Fernández, en las nuevas generaciones de autores chilenos como Aste ${ }^{[88]}$, Altamirano \& Muñoz ${ }^{[89]}$, Pérez ${ }^{[90]}$ y Zavala ${ }^{[91]}$.

\title{
Conclusiones
}

La influencia romano-germánica se ha constituido en la fuente incipiente del derecho tributario en Latinoamérica, sin embargo, las corrientes detractoras de los italianos Benvenuto Griziotti y Oreste Ranelletti no tuvieron un impacto directo, sino que sus teorías fueron introducidas por generaciones posteriores 
de autores, como los italianos Achille Giannini y Dino Jarach, aunque siempre primando las corrientes complementarias de Ranelletti.

Así, a mediados del siglo XX se identifican a lo menos dos formas didácticas para explicar el fenómeno normativo tributario en Latinoamérica: primero, la escuela de Achille Giannini, quien avanzó en la denominada relación jurídico-tributaria, y, segundo, los postulados del italiano Dino Jarach, quien propuso la denominada teoría del hecho imponible. Si bien Jarach tuvo gran influencia en la elaboración del Modelo de Código tributario para América Latina del año 1967. En este texto primó la expresión hecho generador, el que se estaba utilizando en la mayoría de los países latinoamericanos, aunque asumiendo el mismo estatus que el término becho imponible.

En el caso de Chile, el pensamiento de Jarach no fue recogido por la doctrina durante la primera mitad del siglo XX. Al término de esta primera parte, los autores chilenos Mario Fernández y Héctor Fernández, en su obra Principios de derecho tributario, citan a los italianos Achille Giannini y Mario Pugliese, y, a través de este último, llegan a los postulados de Benvenuto Griziotti, sin lograr percibir las corrientes detractoras del autor italiano Oreste Ranelletti. Esta frugal fuente bibliográfica no es suficiente para postular como una teoría lo que Mario Fernández y Héctor Fernández denominaron como hecho gravado, presentando contradicciones al posicionar dicho término tanto en el ámbito de las normas jurídicas generales y abstractas como en el mundo de los hechos.

Desde un punto de vista diacrónico, a partir de la segunda mitad del siglo XX, la doctrina de Jarach logró una mayor aproximación en la doctrina chilena. Así, en 1969, el autor chileno Pedro Massone recurre a la principal obra de Jarach El hecho imponible, pero prefiriendo como denominación la expresión hecho jurídico tributario, que es el mismo título que asumió su libro.

Si bien la obra de Massone es la que ha generado mayor impacto en los nuevos autores del derecho tributario chileno, presenta las mismas dificultades que la obra de Jarach, es decir, posicionó el hecho jurídico tributario tanto en el ámbito de las normas jurídicas generales y abstractas como en el mundo de los hechos. Esto demuestra que el Hecho jurídico tributario de Massone presenta falta de coherencia interna, análisis que fue trasladado a su libro Principios de derecho tributario, hasta la cuarta edición del año 2016, impactando, además, a una nueva generación de autores chilenos.

\section{Bibliografía}

Abundio Pérez, Manual de código tributario (6a ed., Lexis Nexis, 2008).

Achille Giannini, Il rapporto giuridico di imposta, (1 ${ }^{\text {a }}$ ed., Editorial Giuffrè, 1937).

Achille Giannini, Instituciones de derecho tributario (1 $1^{\text {a }}$ ed., Editorial de Derecho Financiero, 1957).

Albert Hensel, Diritto tributario (1 ${ }^{\text {a }}$ ed., Editorial Giuffrè, 1956).

Alfredo Brahm, Impuesto a la renta (1 ${ }^{a}$ ed., Editorial Jurídica de Chile, 1968).

Álvaro Rencoret, Derecho tributario, el impuesto sobre la renta (1ª ed., Editorial Jurídica de Chile, 1950).

Amílcar de Araújo, Fato gerador da obrigação tributária, 6 (1ª ed., Ediçoes Financeiras, 1964).

Andrea Amatucci, La cuestión metodológica entre los teóricos viejos y nuevos y la autonomía científica del derecho tributario, en La autonomía del derecho de hacienda pública y del derecho tributario, 41-77 (Mauricio Plazas, coords., Editorial Universidad del Rosario, 2008).

Andrea Amatucci, La enseñanza del derecho financiero en Italia y España, en Revista de Derecho de la Universidad Andina Simón Bolivar de Ecuador, 123-158 (Quito, 2003).

Andréa Darzé, Responsabilidade tributária, solidariedade e subsidiariedade (1ª ed., Editora Noeses, 2010).

Angela da Motta Pacheco, Ficçôes jurídicas tributárias (Tesis de doctorado en derecho de la Pontificia Universidad Católica de São Paulo, 2006).

Antonio Berliri, Principî di diritto tributario, 12 (2a ed., Editorial Giuffrè, 1967). 
Arturo Huenchullan, Exenciones, franquicias y beneficios de carácter tributario en la legislación sobre viviendas económicas ( $1^{\text {a }}$ ed., Editorial Jurídica de Chile, 1967).

Benvenuto Griziotti, Principios de política, derecho y ciencia de la hacienda (2a ed., Editorial Reus, 1958).

Carlos Cunha, $\mathrm{O}$ simples nacional, a norma tributária e o princípio federativo ( $1^{\mathrm{a}}$ ed., Juruá Editora, 2011).

Carlos Fonrouge, Derecho financiero (6a ed., Editorial Depalma, 1997).

Christian Aste, Curso sobre derecho y código tributario, 184 ( $7^{\mathrm{a}} \mathrm{ed}$. ., Thomson Reuters, 2016).

Código tributario de Bolivia. Ley 2492 de 2003. Art. 16. 2 de agosto de 2003 (Bolivia).

Código tributario de Perú. Decreto 133-2013-EF. Art. 2.22 de junio de 2013 (Perú).

Código tributario de Uruguay. Ley 14.306 de 1974. Arts. 24.29 de noviembre de 1974 (Uruguay).

Código Tributario ecuatoriano. Oficio 189-CLC-CN. Art 16. 14 de julio del 2005 (Ecuador).

Dino Jarach, Curso superior de derecho tributario ( $2^{\mathrm{a}} \mathrm{ed}$., Liceo Profesional CIMA, 1969).

Dino Jarach, El hecho imponible ( $3^{a}$ ed., Abeledo-Perrot, 2004).

Dino Jarach, Estrutura e elementos da relação jurídico-tributária, en Revista de direito público, V. 16 (1971).

Dino Jarach, Hermenêutica no direito tributário, en Interpretação no direito tributário, a cura di (Geraldo Ataliba eds., Ed. Saraiva, 1975).

Eduardo Aldunate, Aproximación conceptual y crítica al neoconstitucionalismo, XXIII Revista de derecho, n. ${ }^{\circ}$ 1, 79-102 (2010).

Eduardo Ferreira, Curso de direito tributário (1 $1^{a}$ ed., Editora Noeses, 2013).

Enrique Piedrabuena, Compendio de legislación tributaria chilena (1 $1^{\mathrm{a}}$ ed., Talleres Gráficos El Chileno, 1945).

Enrique Piedrabuena, Manual de derecho financiero ( $1^{a}$ ed., Editorial Jurídica de Chile, 1950).

Ernst Blumenstein, Sistema di diritto delle imposte (1 ${ }^{\mathrm{a}} \mathrm{ed} ., \mathrm{Editorial}$ Giuffrè, 1954).

Estatuto Tributario colombiano. Decreto 624 de 1989. Art 2. 30 de marzo de 1989 (Colombia).

Ezio Vanoni, L'esperienza della codificazione tributaria in Germania, RISS, 735(1937).

Federico Araújo, Lei complementar e normas gerais em matéria tributária (Tesis de maestría en derecho de la Pontificia Universidad Católica de São Paulo, 2007).

Fernando Ferreira, A vinculação das receitas tributárias e as contribuições no sistema tributário nacional (Tesis de maestría en derecho de la Pontificia Universidad Católica de São Paulo, 2006).

Gaston Jezè, O fato gerador do impôsto (contribuição à teoría do crédito de imposto), 2 Revista de Direito Administrativo (1945). https://doi.org/10.12660/rda.v2.1945.8116

Guillermo Echeverria, El impuesto adicional en la nueva ley de impuesto a la renta ( $1^{\text {a }}$ ed., Editorial Jurídica de Chile, 1969).

Günter Schmölders, Teoría general del impuesto (1ª ed., Editorial de Derecho Financiero, 1962).

Héctor Villegas, Curso de finanzas, derecho financiero y tributario (7a ed., Editorial Depalma, 2001).

Heinrich Kruse, Derecho tributario ( $3^{a}$ ed., Editorial de Derecho Financiero, 1978).

Javier Espejo, \& Pedro Montt, Ley de impuesto sobre la renta (1 $1^{a}$ ed., Imprenta Chile, 1954).

Jorge Cárcamo, Análisis práctico del impuesto a la renta (1ª ed., Imprenta Carroza, 1967).

Jorge Ugarte, Historia e índice de las leyes (1931).

José Casás, La codificación tributaria como instrumento de seguridad jurídica, en Estudios de derecho tributario constitucional e internacional: homenaje latinoamericano a Víctor Uckmar, 133-200 (Pistone, Pasquale; Taveira, Heleno, coords., Editorial Depalma, 2005).

José Zavala, Manual de derecho tributario (Thomson Reuters, 2010).

Ley de modernización y simplificación del sistema tributario nacional 6.380 de 2019. 25 de septiembre de 2019 (Paraguay).

Lindor Pérez, José Parga, \& Sergio Pérez, Reforma tributaria (1ª ed., Editorial Jurídica de Chile, 1966). 
Luis Ugas, El Código Tributario (1ª ed., Editorial Jurídica de Chile, 1965).

Marco Altamirano \& Felipe Muñoz, Derecho tributario parte general: determinación de la obligación tributaria, Ed. Lexis Nexis, 73 (2006).

Marina Vieira, Lançamento tributário (Tesis de maestría en derecho de la Pontificia Universidad Católica de São Paulo, 2011).

Mario Fernández, \& Héctor Fernández, Principios de derecho tributario ( $1^{\text {a }}$ ed., Editorial Jurídica de Chile, 1952).

Mario Pugliese, Instituciones de derecho financiero ( $1^{a}$ ed., Fondo de Cultura Económica, 1939).

Maurício Bellucci, Imposto sobre a renda e indenizações (Tesis de maestría en derecho de la Pontificia Universidad Católica de São Paulo, 2008).

Mauricio Beuchot, Hechos e interpretaciones, hacia una hermenéutica analógica, (Fondo de Cultura Económica, 2016).

Mauritânia de Sousa, Lançamento tributário: vícios materiais e formais para fins do art. 173, II, do Código tributário nacional (Tesis de maestría en derecho de la Pontificia Universidad Católica de São Paulo, 2013).

Miguel Leighton, El impuesto a las ganancias de capital (1ª ed., Editorial Jurídica de Chile, 1966).

Natália de Nardi, Hipótese de incidência do ISS (1 $1^{\text {a }}$ ed., Editora Noeses, 2007).

Nicola D’Amati, Derecho tributario, teoría y crítica (1ª ed., Editorial de Derecho Financiero, 1989)

Osvaldo Torres, ¿Cómo hacer la declaración para el impuesto a la renta? (1ª ed., 1951).

Patricio Barros, Un cuarto de siglo de la legislación tributaria en Chile: labor y desenvolvimiento de la Dirección General de Impuestos Internos en sus 25 años de existencia ( $1^{\text {a }}$ ed., Talleres de El Diario Ilustrado, 1927).

Patricio Bernedo, Pablo Camus \& Ricardo Couyoumdjian, 200 años del Ministerio de Hacienda de la República de Chile ( $1^{\text {a }}$ ed., Ministerio de Hacienda, 2014).

Paulo de Barros-Carvalho, Curso de direito tributário (21 a ed., Editorial Saraiva, 2009).

Paulo de Barros-Carvalho, Direito tributário, linguagem e método (5ª ed., Editora Noeses, 2013).

Paulo de Barros-Carvalho, Direito tributário: fundamentos jurídicos da incidência (9a ed., Editora Saraiva, 2012).

Paulo de Barros-Carvalho, Teoria da norma tributária (3a ed., Editorial Max Limonad, 1998).

Pedro Massone, El hecho jurídico tributario (1 $1^{\text {a }}$ ed., Editorial Edeval, 1969).

Pedro Massone, Principios de derecho tributario (4a ed., Legal Publishing, 2016).

Regina Costa, Curso de direito tributário (1 ${ }^{\mathrm{a}}$ ed., Editora Saraiva, 2009).

Ricardo Cavallo, A regra-matriz de incidência da contribuição provisória sobre movimentação financeira e a utilização de seus dados para a fiscalização de outros tributos (Tesis de maestría en derecho de la Pontificia Universidad Católica de São Paulo, 2005).

Ricardo Lobo, As influências germânicas no direito financeiro e tributário brasileiro, 327 Revista Forense, 109-115 (1994).

Rodrigo da Rocha, Fontes do direito tributário: reflexão sobre a vontade na enunciação normativa (Tesis de doctorado en derecho de la Pontificia Universidad Católica de São Paulo, 2012).

Roque Carrazza, Reflexões sobre a obrigação tributária (1ª ed., Editora Noeses, 2010).

Rubens Gomes de Sousa, Estudos de direito tributário (1ª ed., Editorial Saraiva, 1950).

Samuel Pantoja, Nuestra actual legislación tributaria ( $3^{a}$ ed., Talleres Gráficos La Nación, 1943).

Sergio Carvallo, Manual de legislación tributaria, 62 (1ª ed., Editorial Universitaria, 1959).

Sergio Carvallo, Recopilación y análisis de las modificaciones a la legislación tributaria ( $1^{\text {a }}$ ed., Editorial Jurídica de Chile, 1967).

Tárek Moussallem, Fuentes del derecho tributario (1ª ed., Juristas Editores, Juan Carlos Panez Solórzano trad., 2012). Víctor Mena, \& Emilio Charad, Manual de derecho financiero (1 ${ }^{a}$ ed., Editorial Jurídica de Chile, 1954). 


\section{Notas}

* Artículo de investigación. Este artículo tiene como base la investigación desarrollada en mi tesis doctoral titulada La hipótesis jurídica tributaria en las proposiciones normativas en la Ley sobre impuesto a la renta chilena, defendida en junio del año 2016, en la Escuela de Derecho de la Pontificia Universidad Católica de Valparaíso.

[1] Álvaro Rencoret, Derecho tributario, el impuesto sobre la renta, 13 (1ª ed., Editorial Jurídica de Chile, 1950).

[2] Enrique Piedrabuena, Manual de derecho financiero, 15 (1ª ed., Editorial Jurídica de Chile, 1950).

[3] Andrea Amatucci, La cuestión metodológica entre los teóricos viejos y nuevos y la autonomía científica del derecho tributario, en La autonomía del derecho de hacienda pública y del derecho tributario, 41-77, 51 (Mauricio Plazas, coords., Editorial Universidad del Rosario, 2008).

[4] Andrea Amatucci, La enseñanza del derecho financiero en Italia y España, en Revista de Derecho de la Universidad Andina Simón Bolívar de Ecuador, 1, 123-158 (2003).

[5] Benvenuto Griziotti (1884-1956) nació en Pavía, licenciándose en jurisprudencia en el año 1905. Fue alumno de A. Wagner en Berlín, de P. Leroy-Beaulieu en Paris, de V. Pareto en Losana, y en Italia fue alumno de M. Pantaleoni, de A. de Viti de Marco, de R. Benini y de L. Einaudi. Fue fundador de la escuela de Pavía, en la cual, el 23 de febrero de 1920, leyó su prelusión al curso de ciencia de las finanzas y derecho financiero, teniendo entre sus discípulos a Mario Pugliese (1903-1940) y a Ezio Vanoni (1903-1956).

[6] Andrea Amatucci, supra nota 3, 41-77, 51.

[7] Benvenuto Griziotti, Principios de política, derecho y ciencia de la hacienda, 5-6 (2a ed., Editorial Reus, 1958).

[8] Oreste Ranelletti (1868-1956) nacido en Celano, fue discípulo de Vittorio Scialoja (1856-1933). Desarrolló su primera etapa de docencia en la Universidad de Pavía desde el año 1905 hasta 1919, escribiendo durante este período la primera edición de su Corso di diritto finanziario, obra que se constituyó en los cimientos para la construcción de su metodología didáctica de la ciencia jurídica financiera. Desde 1919 hasta el año 1924 impartió clases en la Universidad de Nápoles, asumiendo posteriormente la labor de organizar la nueva Universidad de Milán.

[9] Andrea Amatucci, supra nota 4, 132, 123-158.

[10] Francesco D’Alessio (1886-1949) nació en Montescaglioso; fue autor del Corso di diritto finanziario publicado en el año 1937, del cual se desprende su claro seguimiento a las escuelas de derecho financiero. Asimismo, fue profesor de derecho financiero y ciencias de las finanzas de la Facultad de Jurisprudencia de la Universidad de Nápoles.

[11] Gustavo Ingrosso (1877-1968) nació en Gallipoli. Fue profesor ordinario de contabilidad del Estado y suplente del curso de ciencias de las finanzas y derecho financiero en la Facultad de Jurisprudencia de la Universidad de Nápoles. En el año 1954 publicó un amplio volumen titulado Diritto finanziario, que recogió las precedentes Istituzioni di diritto finanziario, compuestas por tres volúmenes publicados entre 1935 y 1946, el cual también recogió las corrientes de la escuela napolitana de derecho financiero.

[12] Vicenzo Romanelli-Grimaldi (1904-1963) nació en Nápoles. Fue profesor de la Facultad de Jurisprudencia de la Universidad de Nápoles, lugar en donde impartió el curso de ciencias de las finanzas y derecho financiero. En la primera parte del ensayo titulado Metodología del diritto finanziario, publicado en el año 1960 por la revista Rasegna di Diritto Pubblico, RomanelliGrimaldi refutó la metodología elaborada por Griziotti.

[13] Vicenzo Sica (1924-1964) nació en Castel San Giorgio; sucedió a Romanelli-Grimaldi en el curso de ciencias de las finanzas y derecho financiero de la Facultad de Jurisprudencia de la Universidad de Nápoles. Fue autor de una rigurosa monografía titulada Presupuesto del Estado y programación económica-aspectos jurídicos.

[14] Nacido en Nápoles, en 1923, fue autor del libro Corso di diritto finanziario, el cual después cambió de título por Principi di diritto finanziario.

[15] Achille Donato Giannini (1888-1965) nació en Foggia. En 1924 asumió la cátedra de derecho financiero y tributario y, además, el curso de contabilidad del Estado en la Facultad de Jurisprudencia de la Universidad Católica de Milán. En 1943, se hizo cargo del curso de ciencia de las finanzas y derecho financiero, y en el año 1947 se trasladó a la Universidad de Bari, lugar en donde llegó a ser decano de la Facultad de Jurisprudencia hasta su retiro en 1958. Entre sus obras se destacan: Lezioni di diritto finanziario e tributario (1927), Elementi di diritto finanziario e contabilità si Stato (1934), y Elementi di diritto finanziario (1945). En paralelo a estas obras, Giannini publicó importantes artículos relacionados particularmente con el derecho tributario, como fue 
La clasificaciones delle imposte nel diritto tributario, en Studi dedicati alla memoria di Pier Paolo Zanzucchi (1927), e Il rapporto giuridico di imposta (1937). No obstante, su obra más importante fue Istituzione di diritto tributario, cuya primera edición apareció en 1938, que llegó a concretar, en total, nueve ediciones, la última en 1965, el mismo año en que murió. En 1957 apareció en lengua española la primera edición de las Instituciones, a cargo del profesor español Fernando Sainz de Bujanda. Además, no menos importante fue su obra I concetti fondamentali del diritto tributario publicada en 1956.

[16] Achille Giannini, Instituciones de derecho tributario, 63 ( $1^{\text {a }}$ ed., Editorial de Derecho Financiero, 1957). Aunque el concepto de la relación jurídico-tributario ya lo había analizado con anterioridad en su obra Il rapporto giuridico di imposta, 22 (1a ed., Editorial Giuffrè, 1937).

[17] Antonio Berliri, Principî di diritto tributario, 12 (2a ed., Editorial Giuffrè, 1967). Antonio Berliri fue profesor en la Universidad de Bolonia.

[18] Mario Pugliese, Instituciones de derecho financiero, 49 ( $1^{\text {a }}$ ed., Fondo de Cultura Económica, 1939). Mario Pugliese (1903-1940) nació en Bologna y fue profesor de derecho financiero y ciencia de las finanzas en la Universidad de Trieste y del curso de derecho financiero en la Universidad de Córdoba.

[19] Achille Giannini, supra nota 16,35 (1 a ed., Editorial de Derecho Financiero, 1957).

[20] En el mismo sentido ver Nicola D’Amati, Derecho tributario, teoría y crítica, 14 (1 a ed., Editorial de Derecho Financiero, 1989); Albert Hensel, Diritto tributario, 16 (1ª ed., Editorial Giuffrè, 1956); Ezio Vanoni, L'esperienza della codificazione tributaria in Germania, RISS, 735 (1937); Carlos Fonrouge, Derecho financiero, 51 (6a ed., Editorial Depalma, 1997); Günter Schmölders, Teoría general del impuesto, 20 ( $1^{\text {a }}$ ed., Editorial de Derecho Financiero, 1962); Heinrich Kruse, Derecho tributario, 35 ( $3^{\text {a }}$ ed., Editorial de Derecho Financiero, 1978).

[21] La RAO fue elaborada sobre el proyecto propuesto por el alemán Enno Becker (1869-1940), cuyo emprendimiento cobró significación al no contar con un desarrollo, ni siquiera incipiente, de una ciencia del derecho tributario y que, por tanto, debió valerse de los conceptos y enseñanzas que pudo extraer del derecho administrativo, experiencia lograda como magistrado en el Alto Tribunal Administrativo de Oldenburg (José Casás, La codificación tributaria como instrumento de seguridad jurídica, en Estudios de derecho tributario constitucional e internacional: homenaje latinoamericano a Víctor Uckmar, 133-200, 145 (Pistone, Pasquale; Taveira, Heleno, coords., Editorial Depalma, 2005)). Heinrich Kruse sostiene que en 1906 apareció un Grundriss des finanzrechts de la pluma del docente de Innsbruck, Franz Von Myrbach-Rheinfeld, el cual no habría sido conocido por Becker (Heinrich Kruse, Derecho tributario, 36 ( $3^{\text {a }}$ ed., Editorial de Derecho Financiero, 1978)). Así, previo a la codificación tributaria en Alemania, no se presentaban estudios metodológicos asociados al derecho tributario, sino más bien su nacimiento obedeció a circunstancias históricas por las necesidades derivadas al término de la primera guerra mundial. Sólo con posterioridad a la RAO surgieron en Alemania importantes estudios de gran valor científico, tales como la obra de Von Pistorius, titulada Unser steuerrecht, publicada en segunda edición en 1929; la de Hensel titulada Steuerrecht, publicada en tercera edición en 1933; la de Strutz, titulada Grundlehren des steuerrechts, de 1922; la del autor Waldecner, titulada Deutsches steuerrecht, de 1924; la de Friedrichs, titulada Grundzüge des Steuerrechts im Reich und in preussen, de 1925; la de Schranil, titulada Besteuerungsrecht und steueranspruch, de 1925; la de Mirbt, titulada Grundriss des deutschen und preussischen steuerrechts, de 1925; la de Merch, titulada Steuerschuldrecht, de 1926, y la de Buhler, titulada Lehrbuch des steuerrechts, de 1927. Sin embargo, sostiene Kruse, que este auge científico se vio mermado en el transcurso del año 1933, en que la doctrina del derecho positivo fue arrastrada por la resaca de la época, cuyo punto de inicio lo marcó la designación como Secretario de Estado del Ministerio de Hacienda del Reich, a Fritz Reinhardt, un fanático oficial del fiscalismo (Heinrich Kruse, Derecho tributario, 37 ( $3^{\mathrm{a}}$ ed., Editorial de Derecho Financiero, 1978)).

[22] Ricardo Lobo, As influências germânicas no direito financeiro e tributário brasileiro, 327 Revista Forense, 109-115, 112 (1994).

[23] Ezio Vanoni (1903-1956), nació en Morbegno. Fue catedrático de ciencia de las finanzas y derecho financiero en las universidades de Cagliari, Padua, Venecia y Milán; entre sus obras destacan: Natura e interpretazione delle leggi tributarie, de 1932, y Lezioni di scienza delle finanze e diritto finanziario, de 1934.

[24] Albert Hensel, Diritto tributario, 71-72 (1ª ed., Editorial Giuffrè, 1956). Albert Hensel (1895-1933) nació en Berlín. Desde 1923 a 1928 fue profesor extraordinario en la Universidad de Bonn y en 1929 fue profesor ordinario en Königsberg.

[25] Hans Nawiasky (1880-1961), de origen austriaco, fue profesor de la Universidad de Viena y de la Universidad de Munich.

[26] Ernst Blumenstein, Sistema di diritto delle imposte, 387 (1 a ed., Editorial Giuffrè, 1954). Ernst Blumenstein (1876-1951) nació en Berna, fue inicialmente profesor de derecho público y luego de derecho administrativo. También es el autor del manual Schweizerisches Steuerrecht, publicado en Tübingen, en 1926. 
[27] Fernando Sainz de Bujanda (1915-1999) fue catedrático de la Universidad Complutense.

[28] Ramón Valdés (1908-1997) fue profesor de la Universidad de la República Oriental del Uruguay. Desde 1947 a 1989 impartió el curso de finanzas; además, fue profesor de la cátedra de derecho tributario desde 1957 a 1974, y en los años 1988 y 1989 desarrolló el curso de ciencia política financiera.

[29] Carlos Fonrouge (1901-1984) fue profesor de derecho financiero y tributario en la Universidad de Buenos Aires.

[30] Rubens Gomes de Sousa (1913-1973) fue responsable de la primera propuesta de codificación del derecho tributario en Brasil. Sus principales obras son: Compêndio de legislação tributária (1952); Impôsto de renda (1955); Compêndio de legislação tributária para uso das faculdades de ciências econômicas e administrativas (1960); Aspectos jurídicos de la incidencia de la inflación en el sistema tributario (1968); Pareceres (1975), y Comentários ao Código tributário nacional (1985).

[31] La comisión redactora del Modelo de Código Tributario para América Latina estuvo formada por Carlos Fonrouge (Argentina), Rubens Gomes de Sousa (Brasil), Ramón Valdés (Uruguay), Aurelio Camacho (Colombia), Enrique Piedrabuena (Chile), Alonso Beatriz (El Salvador), Carlos Mersán (Paraguay), Enrique Vidal (Perú) y Juan Octavio (Venezuela).

[32] Dino Jarach (1915-1996) nació en Milán. Fue profesor en la Universidad de Córdoba hasta 1951. De 1951 a 1961 impartió las cátedras de finanzas públicas y derecho financiero en el Instituto Tecnológico del Sur y de 1961 a 1974 la cátedra de finanzas públicas en la Facultad de Ciencias Económicas de la Universidad Nacional de Buenos Aires.

[33] Andrea Amatucci, supra nota 3, 41-77, 63.

[34] Andrea Amatucci, supra nota 4, 137, 123-158; Andrea Amatucci, supra nota 3, 41-77, 59.

[35] Andrea Amatucci, La enseñanza del derecho financiero en Italia y España, Revista de Derecho de la Universidad Andina Simón Bolívar de Ecuador, n. ${ }^{\circ}$ 139, 123-158 (2003).

[36] En segunda edición en 1971 y en tercera edición en 1982.

[37] Dino Jarach, El hecho imponible, 73 ( $3^{\text {a }}$ ed., Abeledo-Perrot, 2004).

[38] Íd., 50-64.

[39] Dino Jarach, Curso superior de derecho tributario, 175 (2a ed., Liceo Profesional CIMA, 1969).

[40] Dino Jarach, supra nota 37, XVII.

[41] Dino Jarach, Estrutura e elementos da relação jurídico-tributária, 16 Revista de direito público, 339 (1971).

[42] Dino Jarach, Hermenêutica no direito tributário, en Interpretação no direito tributário, a cura di Geraldo Ataliba, 84 (1975).

[43] Héctor Villegas, Curso de finanzas, derecho financiero y tributario, 273-274 (7a ed., Editorial Depalma, 2001).

[44] Geraldo Ataliba, Hipótesis de incidencia tributaria, 51 (1 $1^{\mathrm{a}}$ ed., Fundación de Cultura Universitaria de Montevideo, 1977).

[45] Gaston Jezè, O fato gerador do impôsto (contribuição à teoría do crédito de imposto), 2 Revista de Direito Administrativo, $52(1945)$.

[46] Rubens Gomes de Sousa, Estudos de direito tributário, 167 (1 $1^{\text {a }}$ ed., Editorial Saraiva, 1950).

[47] Amílcar de Araújo, Fato gerador da obrigação tributária, 6 (1ª ed., Ediçoes Financeiras, 1964).

[48] El artículo 24 del Código Tributario uruguayo indica lo siguiente: "(Hecho generador). El hecho generador es el presupuesto establecido por la ley para configurar el tributo y cuyo acaecimiento origina la existencia de la obligación.Se considera ocurrido y existentes sus resultados: $1^{\circ}$ ) En las situaciones de hecho, desde el momento en que hayan sucedido las circunstancias materiales necesarias para que produzca los efectos que normalmente le corresponden. $2^{\circ}$ ) En las situaciones jurídicas, desde el momento en que estén constituidas de conformidad con el derecho aplicable”. Código tributario de Uruguay. Ley 14.306 de 1974. Arts. 24.29 de noviembre de 1974 (Uruguay). 
[49] El Código Tributario peruano señala en el artículo 2 lo siguiente: "NACIMIENTO DE LA OBLIGACIÓN TRIBUTARIA. La obligación tributaria nace cuando se realiza el hecho previsto en la ley, como generador de dicha obligación". Código tributario de Perú. Decreto 133-2013-EF. Art. 2. 22 de junio de 2013 (Perú).

[50] El artículo 16 del Código Tributario boliviano señala: "(Definición). Hecho generador o imponible es el presupuesto de naturaleza jurídica o económica expresamente establecido por Ley para configurar cada tributo, cuyo acaecimiento origina el nacimiento de la obligación tributaria”. Código tributario de Bolivia. Ley 2492 de 2003. Art. 16.2 de agosto de 2003 (Bolivia).

[51] El artículo 2 del Estatuto Tributario colombiano hace referencia al hecho generador en los siguientes términos: "CONTRIBUYENTES. Son contribuyentes o responsables directos del pago del tributo los sujetos respecto de quienes se realiza el hecho generador de la obligación sustancial". Estatuto Tributario colombiano. Decreto 624 de 1989. Art 2. 30 de marzo de 1989 (Colombia).

[52] El artículo 16 del Código Tributario ecuatoriano señala: "Hecho generador. Se entiende por hecho generador al presupuesto establecido por la ley para configurar cada tributo". Código Tributario ecuatoriano. Oficio 189-CLC-CN. Art 16. 14 de julio del 2005 (Ecuador).

[53] Véase Ley de modernización y simplificación del sistema tributario nacional, № 6.380 de 2019, promulgada el 25 de septiembre de 2019: "El hecho generador es el presupuesto establecido por la ley para tipificar el tributo y cuya realización origina el nacimiento de la obligación”.

[54] Sergio Carvallo, Manual de legislación tributaria, 62 (1ª ed., Editorial Universitaria, 1959).

[55] Patricio Bernedo, Pablo Camus \& Ricardo Couyoumdjian, 200 años del Ministerio de Hacienda de la República de Chile,

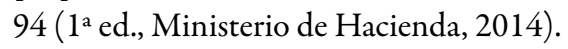

[56] Así se reconoció en la décima cuarta sesión de la Cámara de Diputados de fecha 7 de diciembre de 1923, declarando el Ministro de Hacienda Sr. Ramón Subercaseaux, lo siguiente: "el proyecto de la C. de Ds., inspirado en la ley francesa, creaba el Impuesto sobre cinco categorías de rentas".

[57] Jorge Ugarte, Historia e índice de las leyes, 780 (1931).

[58] Víctor Mena \& Emilio Charad, Manual de derecho financiero, 56 (1ª ed., Editorial Jurídica de Chile, 1954).

[59] Entre estos autores se encuentran: Patricio Barros, Un cuarto de siglo de la legislación tributaria en Chile: labor y desenvolvimiento de la Dirección General de Impuestos Internos en sus 25 años de existencia ( $1^{\mathrm{a}} \mathrm{ed}$., Talleres de El Diario Ilustrado, 1927); Samuel Pantoja, Nuestra actual legislación tributaria ( $3^{a}$ ed., Talleres Gráficos La Nación, 1943); Enrique Piedrabuena, Compendio de legislación tributaria chilena ( $1^{\mathrm{a}}$ ed., Talleres Gráficos El Chileno, 1945). El Texto de Piedrabuena, si bien contiene un detalle bibliográfico, sus alcances se limitan a una descripción de las leyes tributarias vigentes hasta ese entonces.

[60] Eduardo Aldunate, Aproximación conceptual y critica al neoconstitucionalismo, XXIII Revista de derecho, n. ${ }^{\circ}$ 1, 79-102 (2010).

[61] Estas colecciones de las Escuelas de Derecho de la Universidad de Chile fueron creadas con la finalidad de cooperar a la investigación, enseñanza y difusión de las ciencias jurídicas y sociales, dividiéndose en cuatro secciones: manuales jurídicos, estudios jurídicos y sociales, apuntes de clases y memorias de licenciados.

[62] Álvaro Rencoret Bravo fue profesor en la Pontificia Universidad Católica de Chile y se desempeñó como Subdirector General de Impuestos Internos.

[63] Álvaro Rencoret, supra nota 1, 13.

[64] Enrique Piedrabuena (1922-1988) fue profesor en la Universidad de Chile.

[65] Enrique Piedrabuena, supra nota 2, 15. Gran importancia reviste la memoria de pregrado de Enrique Piedrabuena, titulada Compendio de legislación tributaria chilena, publicada en el año 1945, en la cual expuso en forma sintética toda la legislación vigente en Chile acerca de los impuestos y contribuciones, pero sin plantear una tesis doctrinaria o ideológica, como lo reconoce en su prólogo (Enrique Piedrabuena, Compendio de legislación tributaria chilena, 10 ( $1^{\mathrm{a}}$ ed., Talleres Gráfico El Chileno, 1945)), limitando su bibliografía a autores franceses y solamente a dos textos de autores italianos, Principes de science des finances (1928) de Francesco Nitti e Instituciones de derecho financiero (1937) de Mario Pugliese.

[66] Osvaldo Torres, ¿Cómo hacer la declaración para el impuesto a la renta?, 3 (1ª ed., 1951). 
[67] Mario Fernández Provoste dictó la cátedra legislación tributaria en la Universidad de Chile, mientras que Héctor Fernández Provoste se desempeñó como profesor de economía en la misma casa de estudios.

[68] Mario Fernández \& Héctor Fernández, Principios de derecho tributario, 16 (1ª ed., Editorial Jurídica de Chile, 1952).

[69] Íd., 94.

[70] Entiéndase aquí el término texto como objeto del mundo físico en el que se plasman los enunciados, esto es, tinta sobre papel. Algunos autores como el Mauricio Beuchot otorgan al término texto un sentido más amplio, esto es, “[...] no son solo los escritos, sino también los hablados, los actuados y aun de otros tipos; un poema, una pintura y una pieza de teatro son ejemplos de textos. Van, pues, más allá de la palabra y el enunciado" (Mauricio Beuchot, Hechos e interpretaciones, hacia una hermenéutica analógica, 13 (Fondo de Cultura Económica, 2016)). Cabe precisar que Beuchot utiliza este sentido amplio con la finalidad de poder explicar la hermenéutica analógica, como una postura intermedia entre las hermenéuticas unívocas (que pretenden una exactitud a partir de la literalidad del texto) y las equívocas (que se entregan a una interpretación sin límite, más allá de la literalidad del texto).

[71] Mario Fernández \& Héctor Fernández, supra nota 68, 331.

[72] Víctor Mena Vergara fue profesor y decano de la Universidad Central de Chile.

[73] Emilio Charad Dahud fue profesor de la Universidad de Chile.

[74] Entre estos autores se encuentran: Javier Espejo \& Pedro Montt, Ley de impuesto sobre la renta ( $1^{\mathrm{a}}$ ed., Imprenta Chile, 1954); Luis Ugas, El Código Tributario (1ª ed., Editorial Jurídica de Chile, 1965); Lindor Pérez, José Parga \& Sergio Pérez, Reforma tributaria ( $1^{a}$ ed., Editorial Jurídica de Chile, 1966); Sergio Carvallo, Recopilación y análisis de las modificaciones a la legislación tributaria ( $1^{a}$ ed., Editorial Jurídica de Chile, 1967); Jorge Cárcamo, Análisis práctico del impuesto a la renta ( $1^{\text {a }}$ ed., Imprenta Carroza, 1967), y Alfredo Brahm, Impuesto a la renta (1ª ed., Editorial Jurídica de Chile, 1968).

[75] Entre estos autores se encuentran: Miguel Leighton, El impuesto a las ganancias de capital (1 ${ }^{\text {a }}$ ed., Editorial Jurídica de Chile, 1966); Arturo Huenchullan, Exenciones, franquicias y beneficios de carácter tributario en la legislación sobre viviendas económicas ( $1^{a}$ ed., Editorial Jurídica de Chile, 1967); Eduardo Carrillo \& Tulio Carrillo, Tributación normal a la renta de las empresas en Chile y en la legislación comparada (1ª ed., Editorial Jurídica de Chile, Santiago, 1968), y Guillermo Echeverria, El impuesto adicional en la nueva ley de impuesto a la renta ( $1^{a}$ ed., Editorial Jurídica de Chile, 1969).

[76] Pedro Massone es profesor emérito de derecho tributario en la Universidad de Valparaíso.

[77] Pedro Massone, El hecho jurídico tributario, 11 (1a ed., Editorial Edeval, 1969).

[78] Pedro Massone, supra nota 77, 12.

[79] Pedro Massone, Principios de derecho tributario, 1451 (4a ed., Legal Publishing, 2016).

[80] Pedro Massone, supra nota 79, 145.

[81] En los último veinte años se ha desarrollado en Brasil una interesante escuela de derecho tributario encabezada por el autor Paulo de Barros-Carvalho, lo que ha dado pie a importantes obras de su autoría (Paulo de Barros-Carvalho, Curso de direito tributário (21 a ed., Editorial Saraiva, 2009); Paulo de Barros-Carvalho, Direito tributário: fundamentos jurídicos da incidência ( $9^{a}$ ed., Editora Saraiva, 2012); Paulo de Barros-Carvalho, Direito tributário, linguagem e método (5a ed., Editora Noeses, 2013); Paulo de Barros Carvalho, Teoria da norma tributária (3a ed., Editorial Max Limonad, 1998) y otros texto en la misma línea (Tárek Moussallem, Fuentes del derecho tributario ( $1^{\text {a }}$ ed., Juristas Editores, Juan Carlos Panez Solórzano trad., 2012); Eduardo Ferreira, Curso de direito tributário ( $1^{\text {a }}$ ed., Editora Noeses, 2013); Carlos Cunha, O simples nacional, a norma tributária e o princípio federativo ( $1^{a}$ ed., Juruá Editora, 2011); Roque Carrazza, Reflexões sobre a obrigação tributária (1 ${ }^{a}$ ed., Editora Noeses, 2010); Andréa Darzé, Responsabilidade tributária, solidariedade e subsidiariedade (1 ${ }^{\text {a }}$ ed., Editora Noeses, 2010); Regina Costa, Curso de direito tributário (1 $1^{\text {a }}$ ed., Editora Saraiva, 2009); Natália De Nardi, Hipótese de incidência do ISS (1 $1^{a}$ ed., Editora Noeses, 2007); Mauritânia de Sousa, Lançamento tributário: vícios materiais e formais para fins do art. 173, II, do Código tributário nacional (Tesis de maestría en derecho de la Pontificia Universidad Católica de São Paulo, 2013); Rodrigo da Rocha, Fontes do direito tributário: reflexão sobre a vontade na enunciação normativa (Tesis de doctorado en derecho de la Pontificia Universidad Católica de São Paulo, 2012); Marina Vieira, Lançamento tributário (Tesis de maestría en derecho de la Pontificia Universidad Católica de São Paulo, 2011); Maurício Bellucci, Imposto sobre a renda e indenizações (Tesis de maestría en derecho de la Pontificia Universidad Católica de São Paulo, 2008); Federico Araújo, Lei complementar e normas gerais em matéria tributária (Tesis de maestría en derecho de la Pontificia Universidad Católica de São Paulo, 2007); Fernando Ferreira, A vinculação das receitas tributárias e as contribuiçôes no sistema tributário nacional (Tesis de maestría en derecho de la Pontificia Universidad Católica de São Paulo, 2006); Angela Da 
Motta Pacheco, Fiçốes jurídicas tributárias (Tesis de doctorado en derecho de la Pontificia Universidad Católica de São Paulo, 2006); y, Ricardo Cavallo, A regra-matriz de incidência da contribuição provisória sobre movimentação financeira e a utilização de seus dadospara a fiscalização de outros tributos (Tesis de maestría en derecho de la Pontificia Universidad Católica de São Paulo, 2005).

[82] Pedro Massone, supra nota 77, 88

[83] Íd.

[84] Pedro Massone, supra nota 77, 61.

[85] Pedro Massone, supra nota 79, $1147 \& 1452$.

[86] Pedro Massone, supra nota 77, 1161.

[87] Pedro Massone, supra nota 79, 1160.

[88] Christian Aste, Curso sobre derecho y código tributario, 184 (7a ed., Thomson Reuters, 2016).

[89] Marco Altamirano \& Felipe Muñoz, Derecho tributario parte general: determinación de la obligación tributaria, Ed. Lexis Nexis, 73 (2006).

[90] Abundio Pérez, Manual de código tributario, 18 (6a ed., Lexis Nexis, 2008).

[91] José Zavala, Manual de derecho tributario, 34 (Thomson Reuters, 2010).

\section{Licencia Creative Commons CC BY 4.0}

Para citar este articulo/To cite this article: Antonio Faúndez-Ugalde, Influencia romano-germánica en el derecho tributario latinoamericano y, en particular, en la doctrina chilena. Análisis sincrónico y diacrónico para la discusión dogmática de hoy, 68 Vniversitas, n. ${ }^{\circ} 139$ (2019). https://doi.org/10.11144/ Javeriana.vj139.irgd 